Trauma Surgery \& Acute Care Open

\title{
Pre-emptive ECMO cannulation in a patient with severe pulmonary hypertension and acute appendicitis undergoing appendectomy
}

\author{
Mahnoor Zia, ${ }^{1,2}$ Jose Muniz Castro, ${ }^{2}$ Hina Faisal, ${ }^{2}$ Daniel J Bonville (D) ${ }^{2}$
}

${ }^{1}$ College of Medicine, Texas A\&M University Health Sciences Center, Houston, Texas, USA 2Department of Surgery, Houston Methodist Hospital, Houston, Texas, USA

Correspondence to Dr Daniel J Bonville; dibonville@ hotmail.com (c) Author(s) (or their employer(s)) 2020. Re-use permitted under CC BY-NC. No commercial re-use. See rights and permissions. Published by BMJ.

\section{To cite: Zia M,}

Muniz Castro J, Faisal $\mathrm{H}$, et al. Trauma Surg Acute Care Open 2020:5:e000610.

\section{WHAT WOULD YOU DO?}

A 30-year-old woman presented with a 2-day history of abdominal pain, nausea, vomiting and fever. She had a medical history of severe pulmonary hypertension, bilateral pulmonary emboli, right heart failure, hypothyroidism and systemic hypertension. She was classified as World Health Organization (WHO) functional class III for pulmonary hypertension. Physical examination was remarkable for tenderness to palpation over the right lower quadrant without rebound. Laboratory evaluation revealed leukocytosis $(18.3 \mathrm{k} / \mu \mathrm{L})$ with left shift (82.5\% neutrophils). CT scan of the abdomen and pelvis was remarkable for distended fluid-filled appendix, with small appendicoliths and surrounding edema (figure 1). The patient was transferred to our facility for a higher level of care requiring cardiopulmonary evaluation and optimization before possible appendectomy. At the time of transfer, she had developed respiratory distress and was admitted directly to the intensive care unit. A right heart catheterization revealed severe pulmonary hypertension with a right ventricular systolic pressure of $120 \mathrm{~mm} \mathrm{Hg}$ and moderate to severe tricuspid regurgitation. The patient was at high risk for right ventricular failure and pulmonary hypertensive crisis. The initial aim was to optimize medical condition of the patient with the hope to avoid operative intervention in this highrisk patient. She was started on sildenafil, intravenous epoprostenol with titration goal of $20 \mathrm{ng}$ / $\mathrm{kg} / \mathrm{min}$, heparin infusion and intravenous piperacillin/tazobactam for medical management of acute

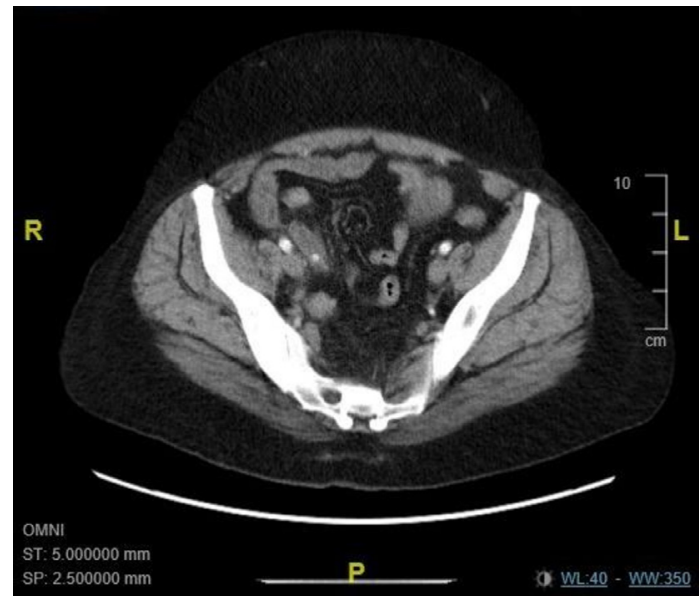

Figure 1 Computed Tomography (CT) remarkable for appendicolith and periappendiceal edema. appendicitis. However, within 24 hours of admission, she developed worsening leukocytosis $(20.7 \mathrm{k} /$ $\mu \mathrm{L})$, fever of $39.1^{\circ} \mathrm{C}$, tachypnea and worsening focal peritonitis.

\section{WHAT DID WE DO AND WHY?}

We initiated surgical planning due to failed nonoperative treatment. Patients with pulmonary hypertension are at increased risk of life-threatening right ventricular failure and decompensation at the induction of general anesthesia. Preoperatively, patient developed severe sepsis and impending shock. Therefore, multidisciplinary preoperative planning included preparation for intraoperative venoarterial extracorporeal membrane oxygenation. Femoral vessel cannulation was performed by cardiovascular surgery under local anesthesia. The femoral artery and vein were cannulated with small sheaths so we could quickly convert to large extracorporeal membrane oxygenation (ECMO) cannulas in case the patient developed cardiogenic shock. This was to avoid the risks that accompany ECMO cannulation (ie, bleeding, dissection and limb ischemia). We also planned for an open procedure to avoid any impairment of venous return to the right heart that might occur as a result of the pneumoperitoneum during a laparoscopic approach.

Following careful induction of general anesthesia, an open appendectomy was performed with a lower midline laparotomy incision below the umbilicus. On entering the abdominal cavity, purulent peritoneal fluid was noted. The appendix was necrotic and gangrenous with multiple perforations. After the appendectomy was completed, the abdominal cavity was irrigated, and the abdomen was then closed with a Jackson-Pratt drain in place. She was extubated and transferred to the intensive care unit in a stable condition without the need for ECMO. The arterial and venous sheaths were removed after the patient improved and her septic shock resolved.

In urgent surgical cases with underlying pulmonary hypertension, recommendations of anesthesia vary between the use of regional anesthesia versus a 'gentle' induction of general anesthesia to prevent arterial hypotension. Additional recommendations include intraoperative monitoring using a transesophageal echo and pulmonary arterial catheter with continuous anticoagulation. However, our patient was not a candidate due to recent hemodynamic decompensation. ECMO is gaining popularity for isolated respiratory or cardiopulmonary 
failure in intraoperative and postoperative settings. If our patient had developed right ventricular failure, intraoperative ECMO would have been lifesaving. Currently, there are no guidelines for the use of ECMO in the setting of acute care surgery. More research is needed to establish guidelines and indications for ECMO and pre-emptive cannulation in the setting of acute care surgeries.

Naturally, it is worth mentioning that there is probably no role of laparoscopic or minimally invasive surgery in these scenarios. An open surgical approach is essential to avoid unintended physiological consequences of high intra-abdominal pressure and to minimize intraoperative time.

Postoperatively, the patient recovered from the surgery perspective. Hospital course was prolonged due to medical management for pulmonary hypertension and decompensated right ventricular failure. Of note, our patient did not require ECMO postoperatively. She was discharged on postoperative day 18 on sildenafil, bumetanide, macitentan and intravenous epoprostenol with titration goal of $30 \mathrm{ng} / \mathrm{kg} / \mathrm{min}$ for 30 days. On outpatient follow-up, the patient was progressing medically; she was tolerating her medication regimen without significant side effects.

We believe the physiologic insult of intra-abdominal sepsis on a tenuous patient with severe pulmonary hypertension warrants early transfer to a tertiary referral center with advanced cardiopulmonary capabilities, an early multidisciplinary approach and consideration of pre-emptive cannulation in preparation for ECMO before induction of anesthesia. This report adds evidence in literature regarding the consideration to use ECMO as needed in appropriate patients with general surgery emergencies.

Acknowledgements All contributors meet the criteria for authorship. Collaborators No collaborators,

Contributors DJB contributed the manuscript idea and editing of the manuscript. MZ and JMC contributed to the literacy search and writing substantial portions of the manuscript. HF contributed to writing and editing portions of the manuscript.

Funding The authors have not declared a specific grant for this research from any funding agency in the public, commercial or not-for-profit sectors.

Competing interests None declared.

Patient consent for publication Obtained.

Ethics approval Our institution does not require study approval for case presentations.

Provenance and peer review Not commissioned; internally peer reviewed.

Open access This is an open access article distributed in accordance with the Creative Commons Attribution Non Commercial (CC BY-NC 4.0) license, which permits others to distribute, remix, adapt, build upon this work non-commercially, and license their derivative works on different terms, provided the original work is properly cited, appropriate credit is given, any changes made indicated, and the use is non-commercial. See: http://creativecommons.org/licenses/by-nc/4.0/.

ORCID iD

Daniel J Bonville http://orcid.org/0000-0002-4763-6925 